\title{
Clinical characteristics of invasive pulmonary aspergillosis in patients with COVID-19 in Zhejiang, China: a retrospective case series
}

\author{
Jie Wang ${ }^{1 \dagger}$, Qing Yang ${ }^{2 \dagger}$, Piaopiao Zhang ${ }^{2 \dagger}$, Jifang Sheng ${ }^{2}$, Jianying Zhou ${ }^{1}$ and Tingting $\mathrm{Qu}^{2,3^{*}}$
}

Keywords: COVID-19, SARS-CoV-2, Invasive pulmonary aspergillosis, Bronchoscopy

To date, COVID-19 has been pandemic across the whole world, whereas around $20 \%$ of patients require treatment in intensive care units (ICUs) $[1,2]$. However, the clinical characteristics and risk factors of IPA in patients with COVID-19 are not well defined. We collected clinical data for 104 patients with COVID-19 between January and March 2020 in the First Affiliated Hospital of Zhejiang University, China. All patients were diagnosed with COVID-19 by positive PCR results. IPA was defined based on proven or probable criteria according to the revision and update of the European Organization for Research and Treatment of Cancer and the Mycoses Study Group Education and Research Consortium [3]. All the statistical analyses were done with the SPSS software 25.0.

As shown in Table 1, of the 104 patients with COVID19, 8 (7.7\%) patients had IPA diagnosed, with obviously older age than the patients without IPA (73 years \pm 13 years vs 53 years \pm 15 years; $P<.001$ ). All the 8 patients were male and had IPA diagnosed after SARSCov-2-negative results were obtained. IPA was diagnosed a median of 21 days after the onset of COVID-19 symptoms and a median of 19 days after admission. Aspergillus was cultured positive from the sputum or bronchoalveolar lavage fluid (BALF) samples of the 8 patients (4 cases from sputum and 4 cases from BALF), and all the 8 cases were Aspergillus fumigatus. Among the 8 patients co-infected with SARS-CoV-2 and Aspergillus, 6 patients were administrated with glucocorticoids, 4 patients mechanical ventilation, 1 patient continuous renal replacement therapy (CRRT)-supported, and 1 patient extracorporeal membrane oxygenation (ECMO)-supported before IPA occurrence. There were significant differences in hypertension, COPD, and chronic kidney disease between the Aspergillus-positive and Aspergillus-negative groups $(P<.05)$. Prior to the development of IPA, $50.0 \%$ vs $11.5 \%$ of patients in the Aspergillus-positive and Aspergillus-negative groups required mechanical ventilation support, respectively $(P<.05)$. Most patients in the 2 groups received glucocorticoids ( $75.5 \%$ vs $59.4 \%$, respectively). There were no significant differences in maximum methylprednisolone equivalent dosage between the 2 groups (methylprednisolone, $40-80 \mathrm{mg} /$ daily). Multivariate analysis showed

* Correspondence: qutingting@zju.edu.cn

${ }^{\dagger}$ Jie Wang, Qing Yang and Piaopiao Zhang contributed equally to this work.

${ }^{2}$ State Key Laboratory for Diagnosis and Treatment of Infectious Disease, The

First Affiliated Hospital, Zhejiang University School of Medicine, 79\#

Qingchun East Road, Hangzhou 310001, Zhejiang, China

${ }^{3}$ Infection Control Department, The First Affiliated Hospital, Zhejiang

University School of Medicine, Hangzhou, Zhejiang, China

Full list of author information is available at the end of the article 
Table 1 Clinical features and selected laboratory abnormalities of COVID-19 patients with or without Aspergillus infection

\begin{tabular}{|c|c|c|c|}
\hline Variable & Aspergillus positive $(n=8)$ & Aspergillus negative $(n=96)$ & $P$ value \\
\hline \multicolumn{4}{|l|}{ Demographics } \\
\hline Age, mean (SD), years & $73(13)$ & $53(15)$ & $<0.001$ \\
\hline Male sex, no. (\%) & $8(100)$ & $54(56.3)$ & 0.02 \\
\hline \multicolumn{4}{|l|}{ Underlying disease, no. (\%) } \\
\hline Any & $7(87.5)$ & $36(37.5)$ & 0.008 \\
\hline Hypertension & $7(87.5)$ & $31(32.3)$ & 0.003 \\
\hline Diabetes mellitus & $2(25)$ & $11(11.5)$ & 0.262 \\
\hline Heart disease & $1(12.5)$ & $6(6.3)$ & 0.439 \\
\hline COPD & $2(25)$ & $2(2.1)$ & 0.029 \\
\hline Cancer & $0(0)$ & $1(1.0)$ & 1 \\
\hline Immunodeficiency & $0(0)$ & $0(0)$ & - \\
\hline Chronic kidney disease & $2(25)$ & $0(0)$ & 0.005 \\
\hline Pregnancy & $0(0)$ & $3(3.1)$ & 1 \\
\hline Smoking in the past 1 year, no. (\%) & $2(25)$ & $6(6.3)$ & 0.115 \\
\hline Severe/critical type, no. (\%) & $8(100)$ & $70(72.9)$ & 0.196 \\
\hline \multicolumn{4}{|l|}{ Complications, no. (\%) } \\
\hline ARDS & $4(50)$ & 38 (39.6) & 0.712 \\
\hline Shock & $0(0)$ & $0(0)$ & - \\
\hline Liver damage & $1(12.5)$ & $7(7.3)$ & 0.485 \\
\hline Acute kidney injury & $1(12.5)$ & $0(0)$ & 0.077 \\
\hline \multicolumn{4}{|l|}{ Treatment, no. (\%) } \\
\hline Mechanical ventilation & $4(50)$ & $11(11.5)$ & 0.014 \\
\hline ECMO & $1(12.5)$ & $3(3.1)$ & 0.278 \\
\hline CRRT & $1(12.5)$ & $1(1.0)$ & 0.149 \\
\hline Corticosteroid treatment, no. (\%) & $6(75)$ & $57(59.4)$ & 0.475 \\
\hline Maximum methylprednisolone equivalent dosage, median (IQR), mg/day & $70(5-80)$ & $40(0-60)$ & 0.191 \\
\hline Administration of antiviral treatment & $8(100)$ & $89(92.7)$ & 1 \\
\hline Initial antibiotic treatment, no./total (\%) & $6(75)$ & $46(47.9)$ & 0.269 \\
\hline 3rd-generation cephalosporin & $0(0)$ & $7(7.3)$ & 1 \\
\hline Fluoroquinolone & $3(37.5)$ & $26(27.1)$ & 0.683 \\
\hline$\beta$-Lactamase inhibitors & $6(75)$ & $17(17.7)$ & 0.001 \\
\hline ICU admission, no./total (\%) & $8(100)$ & $18(18.8)$ & 0 \\
\hline
\end{tabular}

that older age, initial antibiotic usage of $\beta$-lactamase inhibitor combination, mechanical ventilation, and COPD but not hypertension and glucocorticoid therapy were independent risk factors for IPA in patients with COVID-19.

Chest computed tomography (CT) scans of patients with COVID-2019 and IPA are shown in Fig. 1. Among the patients with COVID-2019 and IPA, typical aggressive pneumoconiosis imaging changes were shown in the early phase such as nodules with cavities and dendritic signs. However, in the late phase of the disease, the imaging changes of IPA were atypical, and some lesions might be hidden in the consolidation or interstitial changes. Fibreoptic bronchoscopy showed purulent secretion in the openings of bronchi in some cases. Bronchial ulcer was also found in two patients with COVID-19 and IPA, as shown in Fig. 1c, d. However, a biopsy was not performed because of the severity of cases.

In summary, in our experience, the incidence rate of IPA among the patients with COVID-19 was obviously lower than those among patients with influenza $(7.7 \%$ vs 19\%) [4]. Older age, initial antibiotic usage of $\beta$ lactamase inhibitor combination, mechanical ventilation, 


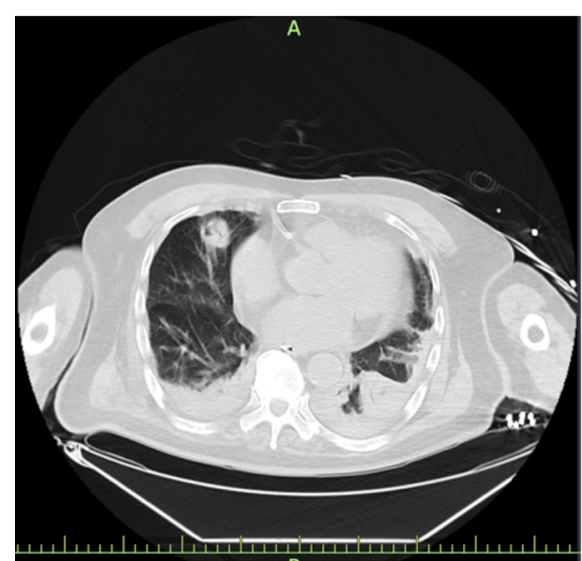

(a)

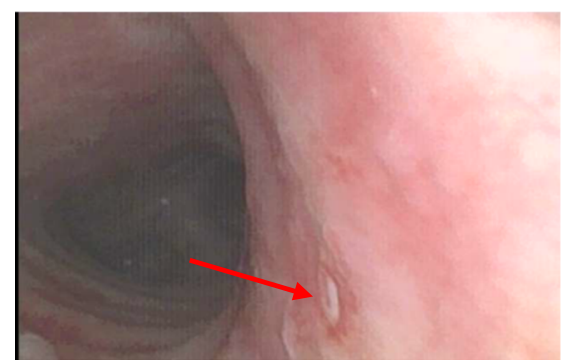

(c)

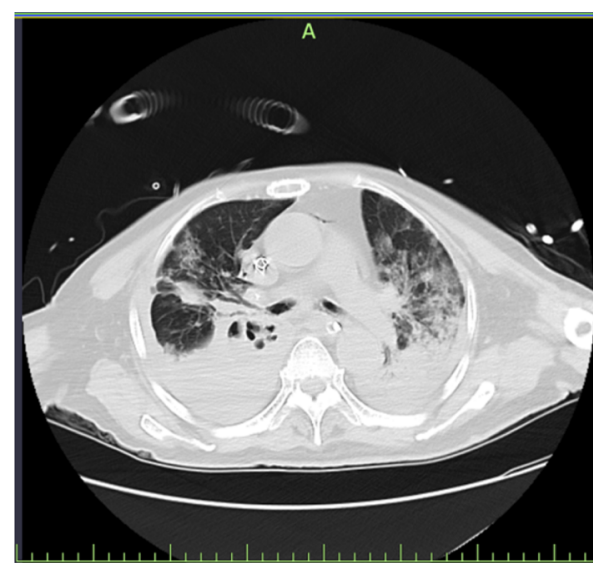

(b)

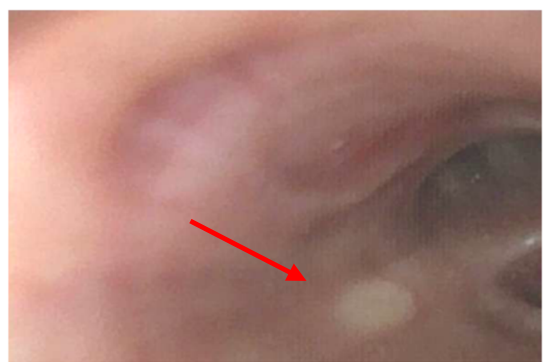

(d)

Fig. 1 Lung CT scans and bronchoscopy findings of patients with COVID-2019 and IPA. Patient 1,90 years, lung CT scan showed nodules with cavities in the middle lobe of the right lung and consolidation bilateral lower lobes with a small amount of pleural effusion (a); bronchoscopy finding showed small ulcer in the right wall of the trachea (c). Patient 2, 74 years, lung CT scan showed consolidation bilateral lower lobes with multiple irregular cavities in the middle (b); bronchoscopy finding showed right middle bronchial ulcer (d). Red arrow indicated the positions of bronchial ulcers

and COPD were the risk factors of IPA among patients with COVID-19. Early intervention with bronchoscopy, observation of changes in the bronchial mucosa, and obtaining evidence of fungal microbiology were important in patients with severe/critical COVID-19.

\section{Acknowledgements}

We are grateful to the Health Commission of Zhejiang Province, China, for coordinating the data collection. Thanks to all the frontline medical staff of Zhejiang Province for their bravery and efforts in COVID-19 prevention and control.

\section{Authors' contributions}

$T Q, J Z$, and JS conceptualized the idea and designed the study. JW drafted the manuscript, and QY revised it. PZ and JW participated in the data collection, analysis, and interpretation. The authors read and approved the final manuscript.

\section{Funding}

This work was supported by the fund of the Zhejiang Province Medical and Health Science and Technology Project [2018KY382], Natural Science Foundation of Zhejiang Province (LED2OH190003) and Zhejiang University Education Foundation (2020XGZX101)

\section{Availability of data and materials}

The datasets and materials used and/or analyzed during the current study are available from the corresponding author on reasonable request.
Ethics approval and consent to participate

This study is reviewed and approved by the ethics committee of the First Affiliated Hospital of Zhejiang University. Following a full explanation of the study, written consent was obtained from each patient or his/her authorized representatives.

\section{Consent for publication}

Not applicable.

\section{Competing interests}

The authors declare that they have no competing interests.

\section{Author details}

${ }^{1}$ Respiratory Department, The First Affiliated Hospital, Zhejiang University School of Medicine, Hangzhou, Zhejiang, China. ${ }^{2}$ State Key Laboratory for Diagnosis and Treatment of Infectious Disease, The First Affiliated Hospital, Zhejiang University School of Medicine, 79\# Qingchun East Road, Hangzhou 310001, Zhejiang, China. ${ }^{3}$ Infection Control Department, The First Affiliated Hospital, Zhejiang University School of Medicine, Hangzhou, Zhejiang, China.

Received: 18 May 2020 Accepted: 28 May 2020

Published online: 05 June 2020

\section{References}

1. Swiss Society Of Intensive Care M. Recommendations for the admission of patients with COVID-19 to intensive care and intermediate care units (ICUs and IMCUs). Swiss Med Wkly. 2020;150:w20227.

2. Liew MF, Siow WT, MacLaren G, See KC. Preparing for COVID-19: early experience from an intensive care unit in Singapore. Crit Care. 2020;24(1):83. 
3. Donnelly JP, Chen SC, Kauffman CA, Steinbach WJ, Baddley JW, Verweij PE, Clancy CJ, Wingard JR, Lockhart SR, Groll AH, et al. Revision and update of the consensus definitions of invasive fungal disease from the European Organization for Research and Treatment of Cancer and the Mycoses Study Group Education and Research Consortium. Clin Infect Dis. 2019. (Epub ahead of print).

4. Schauwvlieghe A, Rijnders BJA, Philips N, Verwijs R, Vanderbeke L, Van Tienen C, Lagrou K, Verweij PE, Van de Veerdonk FL, Gommers D, et al. Invasive aspergillosis in patients admitted to the intensive care unit with severe influenza: a retrospective cohort study. Lancet Respir Med. 2018; 6(10):782-92.

\section{Publisher's Note}

Springer Nature remains neutral with regard to jurisdictional claims in published maps and institutional affiliations.

Ready to submit your research? Choose BMC and benefit from:

- fast, convenient online submission

- thorough peer review by experienced researchers in your field

- rapid publication on acceptance

- support for research data, including large and complex data types

- gold Open Access which fosters wider collaboration and increased citations

- maximum visibility for your research: over $100 \mathrm{M}$ website views per year

At BMC, research is always in progress.

Learn more biomedcentral.com/submissions 